\title{
Additional Outcome Measure
}

National Cancer Institute

\section{Source}

National Cancer Institute. Additional Outcome Measure. NCI Thesaurus. Code C156601.

Additional key measures that will be used to evaluate the intervention(s) or, for

observational studies, that are a focus of the study, but which are not considered primary or secondary outcome measures. 